\title{
PERANCANGAN REDUNDANCY LINK DAN LOAD BALANCING MENGGUNAKAN METODE ETHERCHANNEL LACP DENGAN INTERVLAN ROUTING
}

\author{
Alfin Syaifudin'), Moh. Iwan Wahyuddin 2), Sari Ningsih ${ }^{3)}$ \\ 1,2,3 Informatika, Universitas Nasional \\ 1,2,3 Jalan Sawo Manila, Pasar Minggu, Kota Jakarta Selatan, 12520 \\ Email: 'alfinsimulasi@gmail.com, 2iwan_wyd@yahoo.com, ${ }^{3}$ sariningsih.lectures@yahoo.com
}

\begin{abstract}
The significant increase in the number of network users now needs to be balanced with LAN network infrastructure that has a good level of availability and reliability so that network connectivity is maintained. Connectivity on a LAN network can be disrupted due to problems that arise when the network is used, such as when the twisted pair network cable used is damaged and there is a buildup of network workload on one path. These problems can be overcome by applying one of the technologies on the LAN network, EtherChannel technology, in which this study applies EtherChannel LACP type technology as a redundancy link and load balancing design so that the network schema created an alternative path / redundancy and a network workload balancer system. The use of interVLAN routing type SVI (Switch Virtual Interface) makes VLANs on the network can be connected to each other through virtual interfaces, so that the routing process continues even though one of the links used is damaged and can support the performance of the implementation of EtherChannel technology. From the application of this technology, LAN network problems can be resolved and an increase in network availability and a small risk of overload with good network performance is the condition of 30, 40 and 50 PCs each with an average packet loss value of less than $1 \%$ and a delay of no more than $150 \mathrm{~ms}$.
\end{abstract}

Keywords: EtherChannel, interVLAN routing, load balancing, redundancy link, SVI

\begin{abstract}
Abstrak
Peningkatan jumlah pengguna jaringan yang signifikan saat ini, perlu diimbangi dengan infrastuktur jaringan LAN yang memiliki tingkat ketersediaan dan keandalan yang baik agar konektivitas jaringan tetap terjaga. Konektivitas pada jaringan LAN dapat terganggu akibat masalah yang muncul saat jaringan digunakan, seperti ketika kabel jaringan berjenis twisted pair yang digunakan mengalami kerusakan dan terjadi penumpukan beban kerja jaringan pada satu jalur. Permasalahan tersebut dapat diatasi dengan menerapkan salah satu teknologi pada jaringan LAN yaitu teknologi EtherChannel, di mana pada penelitian ini menerapkan teknologi EtherChannel tipe LACP sebagai rancangan redundancy link dan load balancing sehingga pada skema jaringan yang dibuat terdapat jalur alternatif/redundansi dan sistem penyeimbang beban kerja jaringan. Penggunaan interVLAN routing tipe SVI (Switch Virtual Interface) membuat antar VLAN pada jaringan dapat saling terhubung melalui virtual interface, sehingga proses routing tetap berjalan walaupun salah satu link yang digunakan mengalami kerusakan serta dapat mendukung kinerja dari penerapan teknologi EtherChannel tersebut. Dari penerapan teknologi tersebut, permasalahan jaringan LAN dapat teratasi dan didapatkan peningkatan ketersediaan jaringan serta kecilnya resiko overload dengan performa jaringan yang baik yaitu pada kondisi 30, 40 dan 50 PC tiap rata-rata nilai packet loss kurang dari 1\% dan delay tidak lebih dari $150 \mathrm{~ms}$.
\end{abstract}

Kata Kunci: EtherChannel, interVLAN routing, load balancing, redundancy link, SVI

\section{Pendahuluan}

Pada suatu organisasi, kantor ataupun perusahaan dibutuhkan infrastruktur jaringan yang dapat menyediakan kebutuhan dari para pengguna dan memiliki keandalan dalam menangani beban kerja jaringan yang ada. Oleh sebab itu dibutuhkan suatu skema jaringan berkualitas yang memiliki ketersediaan yang tinggi (high availability) dan keandalan yang tinggi (high reliability) dalam implementasinya [1].

Konektivitas pada jaringan LAN dapat terganggu akibat permasalahan yang muncul saat jaringan digunakan, salah satunya ialah ketika peningkatan jumlah pengguna yang signifikan, namun melebihi batas kapasitas bandwidth yang tersedia. Hal tersebut dapat mengakibatkan overload pada jalur jaringan dan menurunkan performansi jaringan itu sendiri [2].

Permasalahan juga dapat terjadi ketika gangguan fisik pada kabel jaringan LAN (Local Area Network) berjenis twisted pair yang digunakan mengalami kerusakan. Sehingga pengguna jaringan tidak dapat terkoneksi dengan public network maupun local network secara optimal yang mana dapat mengganggu proses kinerja dari instansi itu sendiri [3]. 
Dalam mengatasi permasalahan yang muncul, beberapa penelitian sebelumnya menerapkan perancangan redundancy link dan load balancing pada jaringan LAN menggunakan metode EtherChannel. Redundancy link ialah suatu jalur jaringan alternatif yang digunakan untuk meningkatkan ketersediaan jaringan, sehingga saat suatu jaringan memiliki jalur (link) yang terputus, maka terdapat jalur lain yang bisa dilewati untuk pengiriman data tanpa mempengaruhi konektivitas jaringan tersebut [4].

Load balancing merupakan sistem yang digunakan untuk mendistribusikan atau menyeimbangkan beban traffic pada dua atau lebih jalur jaringan, sehingga dapat mencegah terjadinya penumpukan beban traffic pada satu jalur jaringan (overload) dan traffic tetap dapat berjalan dengan optimal [5].

Pada penelitian ini akan menerapkan teknologi EtherChannel tipe LACP (Link Aggregation Control Protocol) sebagai redundancy link dan load balancing yang ditujukan untuk mencegah keterlambatan pengiriman data saat kondisi down karena salah satu jalur jaringan terputus serta mencegah terjadinya overload karena beban kerja jaringan menumpuk pada satu jalur saja. Selain itu teknologi tersebut juga memiliki kelebihan antara lain dapat meningkatkan bandwitdh, konvergensi yang cepat, multiple platform, dan kemudahan dalam manajemen [6].

Penggunaan InterVLAN routing tipe SVI (Switch Virtual Interface) juga ditujukan untuk menghubungkan antar network ataupun VLAN yang berbeda melalui interface virtual, sehingga pada port fisik tidak perlu diasosiakan dengan IP address untuk default gateway. Protokol VTP juga diterapkan untuk memudahkan pengelolaan VLAN pada jaringan LAN agar lebih terorganisir, efisien dan konsistensi database VLAN tetap terjaga [7-8].

\section{Metode Penelitian}

Penelitian ini menggunakan metode teknologi EtherChannel LACP dengan interVLAN routing dalam perancangan infrastruktur jaringan yang dibuat dan disimulasikan menggunakan aplikasi simulator GNS3.

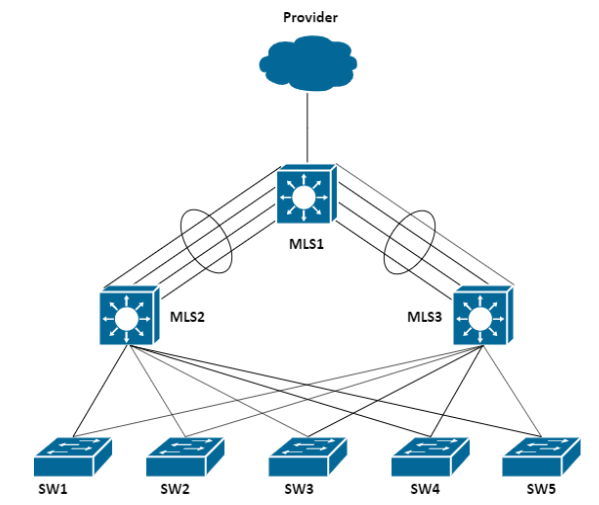

Gambar 1. Desain Topologi Hierarchical

Desain topologi tersebut merupakan topologi yang akan diterapkan dengan mengimplementasikan teknologi
EtherChannel tipe LACP sebagai rancangan jalur alternatif (redundancy link) dan penyeimbang beban kerja dalam jaringan (load balancing), serta interVLAN routing tipe SVI digunakan untuk menghubungkan antar VLAN atau network yang berbeda. Pengelolaan jaringan LAN menggunakan VLAN dengan protokol VTP untuk membagikan informasi database VLAN sehingga konsistensi database VLAN tetap terjaga.

\section{EtherChannel Tipe LACP}

EtherChannel merupakan suatu teknologi yang digunakan pada perangkat jaringan Cisco yaitu mengikat dua atau lebih physcial link menjadi satu logical link dalam satu buah port group. Maksimal port atau link yang dapat diikat untuk tiap EtherChannel ialah sebanyak 8 port, dengan ketentuan setiap port tersebut memiliki konfigurasi interface yang sama dalam hal speed, duplex, dan trunking encapsulation protocol.

EtherChannel tipe LACP (Link Aggregation Control Protocol) yaitu teknologi EtherChannel yang menggunakan protokol open standard milik IEEE (802.3ad) dan memiliki kelebihan berupa kemudahan dalam berkolaborasi dengan environment yang berbeda. Setiap interface perangkat yang akan diikat perlu dikonfigurasi mode active atau passive. Interface yang dikonfigurasi mode active akan memulai negosiasi EtherChannel dan interface mode passive akan merespon LACP request dari interface active.

\section{InterVLAN Routing}

InterVLAN routing adalah metode yang digunakan untuk melakukan routing antar VLAN atau meneruskan traffic antar VLAN yang telah didaftarkan agar bisa saling terkoneksi satu sama lain, walaupun memiliki VLAN ID dan network yang berbeda. Pada interVLAN routing tipe SVI (Switch Virtual Interface) akan dibuat vitual interface untuk VLAN sesuai dengan VLAN ID yang telah didaftarkan dan diasosiasikan dengan default gateway masing-masing VLAN, sehingga dapat saling terhubung. InterVLAN routing tipe SVI dapat meneruskan packet melalui link lain yang tersedia ketika link yang digunakan mengalami kerusakan, sehingga menghasilkan konvergensi yang cepat dan memiliki fleksibilitas yang baik.

\section{VTP(VLAN Trunking Protocol)}

VLAN (Virtual Local Area Network) merupakan metode dalam jaringan komputer untuk membuat suatu jaringan yang secara logika berdiri sendiri namun berada pada jaringan LAN yang sama, sehingga dapat terbentuk satu atau lebih VLAN pada sebuah jaringan LAN. Untuk menghindari inkonsistensi data VLAN dan mempermudah dalam pengelolaannya digunakan suatu protokol yang bernama VTP. VTP (VLAN Trunking Protocol) adalah protokol milik Cisco yang berperan dalam menyebarkan informasi VLAN pada jaringan LAN. Untuk melakukan 
hal tersebut, VTP membawa data VLAN ke semua switch yang terhubung di domain VTP.

Segala konfigurasi perangkat Cisco akan dilakukan melalui CLI (Command Line Interface) pada aplikasi terminal SecureCRT dan disimulasikan dengan aplikasi GNS3. GNS3 (Graphical Network Simulator 3) merupakan aplikasi simulasi jaringan komputer berbasis GUI (Graphical User Interface) yang bersifat open source dan banyak digunakan para network engineer untuk merancang dan menganalisa skema jaringan yang dibuat. GNS3 mampu mensimulasikan jaringan yang kompleks dan memiliki berbagai fitur yang dapat digunakan untuk keperluan design, testing, training dan experimental dengan menggunakan IOS router dan switch secara real.

\section{Flowchart Perancangan Jaringan}

Proses perancangan jaringan yang menerapkan redundancy link dan load balancing mulai dari analisa kebutuhan hardware dan software hingga analisa QoS dapat dilihat seperti pada gambar flowchart berikut.

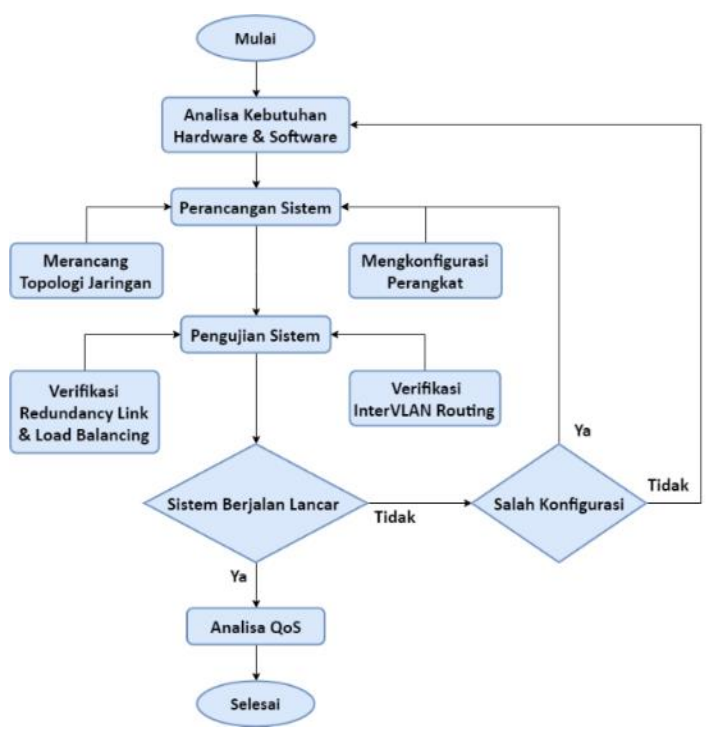

Gambar 2. Flowchart Perancangan Jaringan

Berdasarkan flowchart yang telah dibuat, tahapan proses perancangan dapat dijelaskan secara ringkas sebagai berikut :

a. Menganalisa kebutuhan hardware dan software yang akan digunakan untuk penelitian.

b. Merancang topologi dan mengkonfigurasi setiap perangkat jaringan yang terhubung.

c. Melakukan pengujian sistem hasil perancangan jaringan, jika sistem bermasalah dan terdapat kesalahan pada konfigurasi maka kembali ke tahap konfigurasi perangkat, jika bukan pada konfigurasi maka dapat dianalisa kembali dari tahap analisa software dan hardware yang digunakan.

d. Menganalisa QoS pada rancangan jaringan yang dibuat setelah sistem berjalan dengan lancar.

\section{Spesifikasi Software dan Hardware}

Pada penelitian ini menggunakan software dan hardware yang ditujukan untuk melakukan simulasi perancangan jaringan dengan spesifikasi seperti pada tabel berikut.

Tabel 1. Spesifikasi Hardware Notebook

\begin{tabular}{cl}
\hline No & \multicolumn{1}{c}{ Hardware } \\
\hline 1 & CPU Intel i5-8250U 1.60GHz $-3.40 \mathrm{GHz}$ \\
2 & VGA NVIDIA GeForce MX150 \\
3 & RAM 12 GB DDR4 \\
4 & SSD 256 GB \\
5 & HDD 1 TB \\
\hline
\end{tabular}

Pada tabel 1 telah disebutkan spesifikasi hardware yang digunakan dalam penelitian, di mana hardware tersebut cukup menghasilkan kinerja yang baik ketika perancangan topologi dan pengkonfigurasian perangkat 3 multilayer switch, 5 switch dan 50 PC client.

Tabel 2. Spesifikasi Software Notebook

\begin{tabular}{cl}
\hline No & \multicolumn{1}{c}{ Software } \\
\hline 1 & OS Windows 10 Home 64-bit \\
2 & GNS3 2.2.3 \\
3 & VMware Workstation Pro 15.5 \\
4 & SecureCRT 8.1.4 \\
5 & Cisco IOSvL2 15.2.1 \\
6 & Wireshark 3.0.6 \\
\hline
\end{tabular}

Pada tabel 2 telah disebutkan spesifikasi software yang mendukung dalam mensimulasikan dan menganalisa perancangan jaringan yang diteliti. Aplikasi GNS3 digunakan untuk melakukan simulasi rancangan jaringan, VMware Workstation untuk memvirtualisasi perangkat sehingga memperingan kinerja pemrosesan, SecureCRT berperan sebagai terminal CLI (Command Line Interface) untuk pengkonfigurasian perangkat, Cisco IOSvL2 merupakan IOS (Internetwork Operating System) yang digunakan untuk perangkat jaringan dan Wireshark berguna untuk meng-capture traffic jaringan.

\section{Hasil dan Pembahasan}

Pada rancangan jaringan akan dianalisa dan dibahas mengenai kinerja redundancy link dan load balancing serta performansi yang dihasilkan berdasarkan skema jaringan yang telah dibuat.

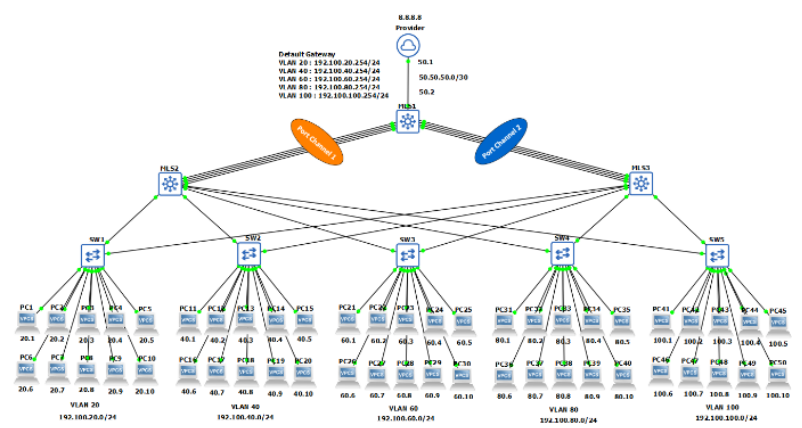


Gambar 3. Topologi Hierarchical Redundancy Link dan Load Balancing

Topologi hierarchical pada gambar 3 telah memiliki redundancy link dan load balancing yang menggunakan teknologi EtherChannel tipe LACP, sehingga tidak perlu khawatir packet mengalami kegagalan dalam proses pengiriman dikarenakan kondisi link yang rusak. Teknologi EtherChannel akan mencari link aktif lainnya dalam port group agar packet tetap dapat terkirim ke tujuan. Teknologi EtherChannel dapat meningkatkan kecepatan koneksi antar switch maupun router dan menyeimbangkan beban kerja jaringan sesuai jumlah link yang diikat sehingga meminimalisir resiko overload saat jaringan digunakan.

Penggunaan interVLAN routing tipe SVI ditujukan untuk meneruskan traffic antar VLAN atau network yang berbeda melaui default gateway yang telah diasosiasikan pada virtual interface. Karena default gateway berada pada virtual interface maka ketika link yang digunakan untuk mengirim packet ke local network mengalami kondisi down, packet akan tetap dapat dikirim melalui link lain yang tersedia pada port group EtherChannel, sehingga ketersediaan jaringan tetap terjaga dan dapat mengoptimalkan kinerja teknologi EtherChannel itu sendiri.

\section{Pengujian EtherChannel Tipe LACP}

Pengujian redundancy link dan load balancing dilakukan pada tahap ini, dengan melakukan pemutusan link ketika proses pengiriman packet dilakukan untuk mengetahui apakah packet tetap dapat sampai ke tujuan atau tidak. Jumlah output packets pada tiap interface EtherChannel juga akan dianalisa saat dilakukan proses flooding untuk mengetahui kinerja dari load balancing. Segala pengujian dan analisa dilakukan sebanyak 30 kali untuk memastikan kinerja perangkat beserta rancangan redundancy link dan load balancing dapat berjalan dengan optimal.

\section{Sebelum Pemutusan 3 Link EtherChannel}

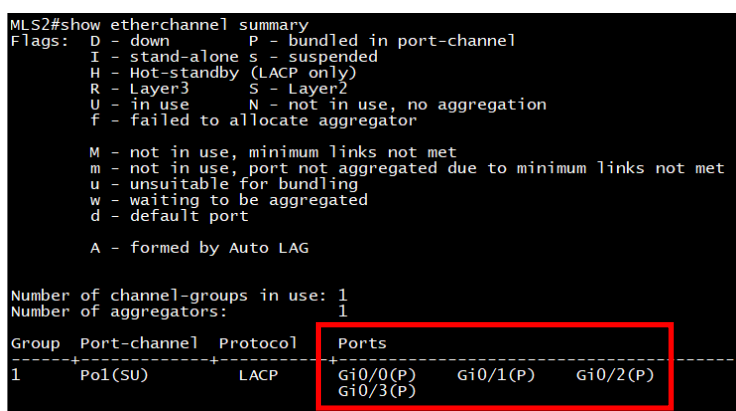

Gambar 4. Kondisi Port Group Pada MLS2 Sebelum 3 Link EtherChannel Diputus

Pada gambar 4 dapat dilihat kondisi Port Group EtherChannel pada MLS2 (multilayer switch 2) yaitu terdapat 4 link yang terhubung berstatus $\mathrm{P}$ (bundled in port) yaitu $\mathrm{Gi} 0 / 0, \mathrm{Gi} / 1$, Gi0/2 dan $\mathrm{Gi} 0 / 3$.

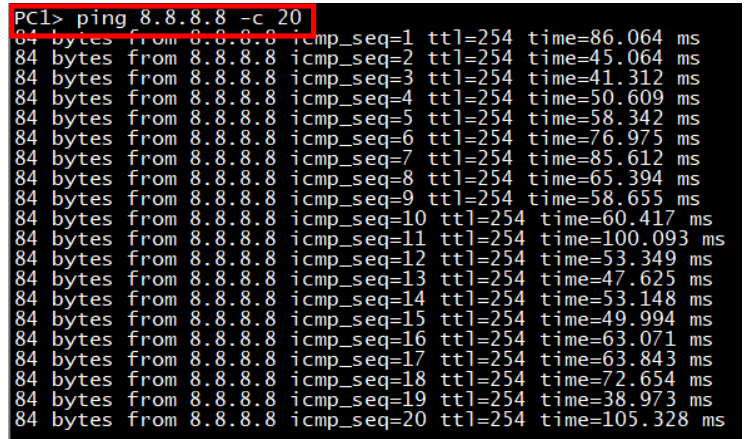

Gambar 5. Kondisi PC client Sebelum 3 Link EtherChannel Diputus

Pada gambar 5 kondisi PC1 dapat mengirim packet secara lancar dengan melakukan ping ke provider sebanyak 20 kali tanpa terjadi kondisi terputus (timeout).

\section{Setelah Pemutusan 3 Link EtherChannel}

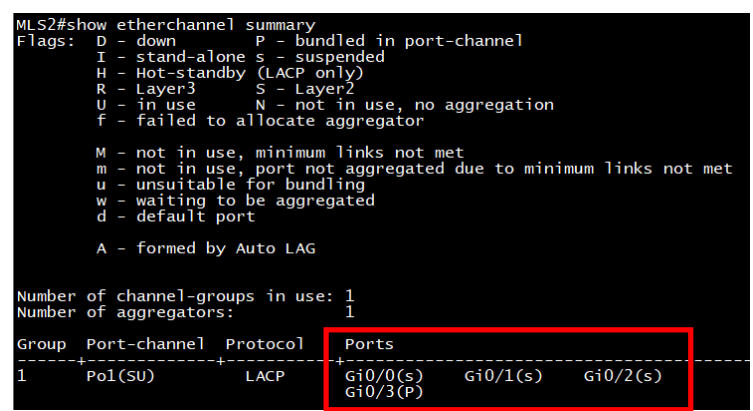

Gambar 6. Kondisi Port Group Pada MLS2 Setelah 3 Link EtherChannel Diputus

Pada gambar 6 dapat dilihat kondisi Port Group EtherChannel terdapat 3 link yang berstatus s (suspended) yaitu Gi0/0, Gi0/1 dan Gi0/2 sebab 3 link tersebut telah diputus. Karena pada tiap Port Group berisi 4 link maka cukup dilakukan pemutusan sebanyak 3 link untuk mengetahui kinerja dari 1 link EtherChannel yang tersisa. Apabila pemutusan lebih dari 3 link maka sistem akan otomatis memindahkan traffic jaringan melalui MLS3 (multilayer switch 3).

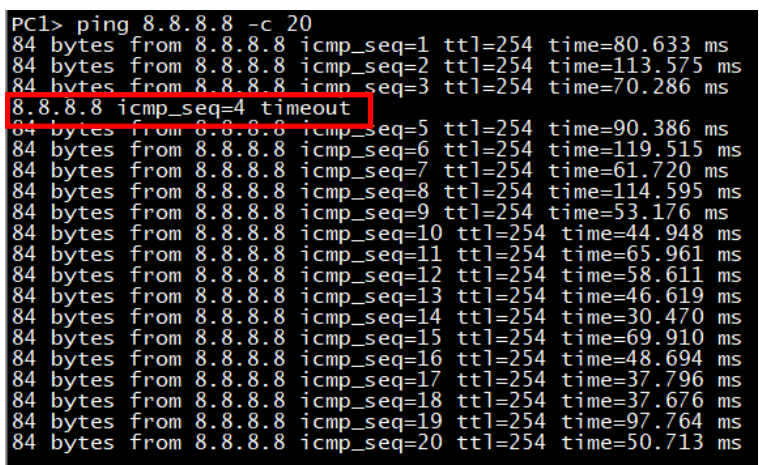

Gambar 7. Kondisi PC client Setelah 3 Link Diputus

Pada gambar 7 ketika PC1 mengirim packet dengan melakukan ping ke provider sempat terjadi kondisi 
timeout (jaringan terputus) ketika 3 link telah diputus, namun packet tetap dapat kembali dikirimkan karena masih terdapat 1 link sebagai jalur alternatif (redundancy link) untuk melanjutkan pengiriman packet yang sempat terhenti.

\section{Pemberian Beban Kerja (Flooding)}

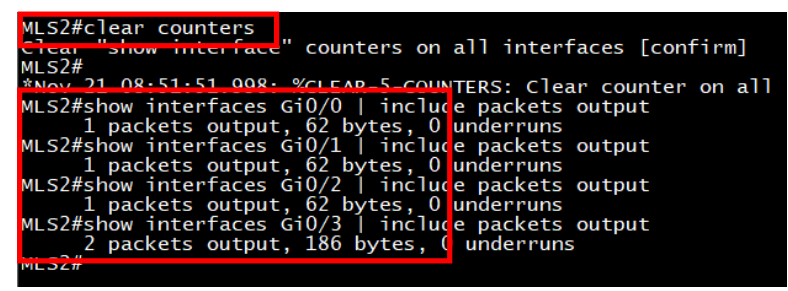

Gambar 8. Jumlah Packets Output Pada MLS2 Sebelum Flooding

Pada gambar 8 jumlah packets output pada tiap interface memiliki jumlah yang sedikit yaitu antara 1 dan 2 setelah dilakukan perintah clear counters untuk membersihkan kalkulasi jumlah packets output pada tiap interface.

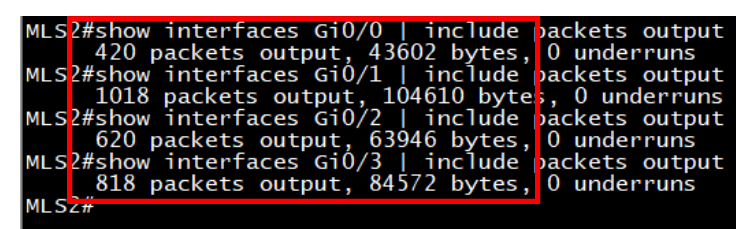

Gambar 9. Jumlah Packets Output Pada MLS2 Setelah Flooding

Pada gambar 9 jumlah packets output tiap interface meningkat tajam setelah dilakukan flooding dengan mengirim packet sebanyak 300 kali melalui 15 PC client secara bersamaan yaitu PC1-PC5, PC11-PC15 dan PC21$\mathrm{PC} 25$. Pada interface $\mathrm{GiO} / 0$ jumlah packets output sebanyak 420, Gi0/1 jumlah packets output sebanyak 1018, Gi0/2 jumlah packets output sebanyak 620 dan Gi0/3 jumlah packets output sebanyak 818 . Hal tersebut menandakan bahwa load balancing telah bekerja karena pengiriman packet saat proses flooding menggunakan semua link EtherChannel.

\section{Pengujian InterVLAN Routing Tipe SVI}

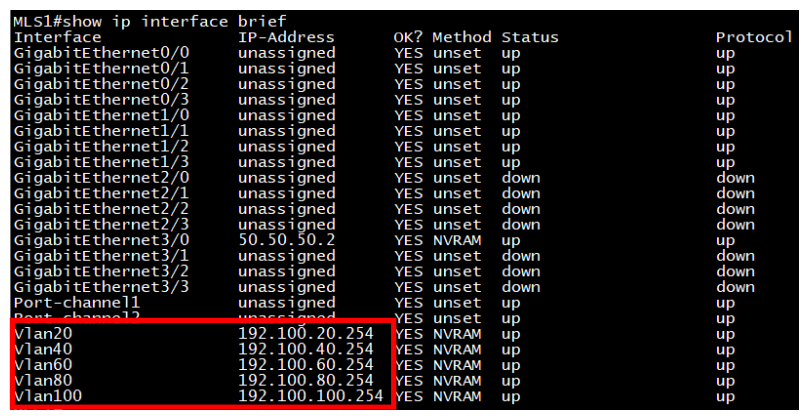

Gambar 10. VLAN Default Gateway Pada MLS1

Pada gambar 10 setiap interface VLAN pada MLS1 (multilayer switch 1) diasosiasikan dengan IP address sebagai default gateway untuk VLAN 20, 40, 60, 80 dan
100 sehingga kelima VLAN tersebut dapat saling terhubung meskipun memiliki network yang berbeda. Pada interface VLAN 20 memiliki IP address 192.100.20.254, interface VLAN 40 memiliki IP address 192.100.40.254, interface VLAN 60 memiliki IP address 192.100.60.254, interface VLAN 80 memiliki IP address 192.100.80.254 dan interface VLAN 100 memiliki IP address 192.100.100.254.

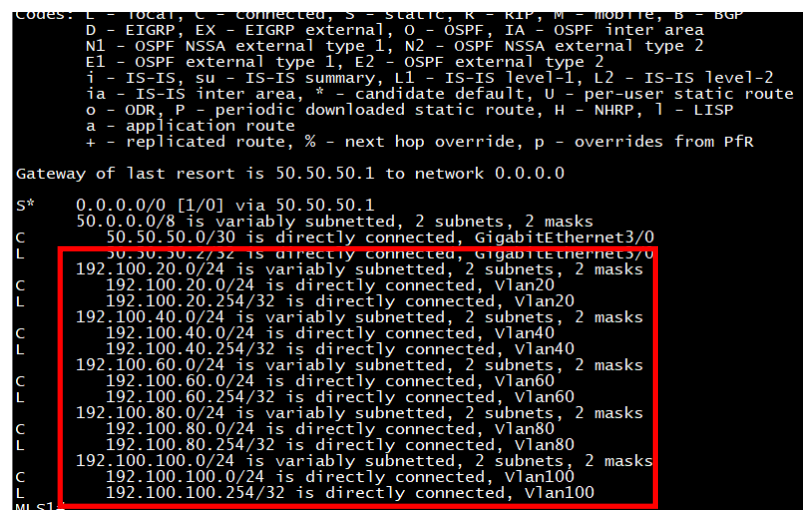

Gambar 11. Routing Table

Pada gambar 11 dapat dilihat bahwa default gateway untuk setiap VLAN yang diasosiasikan telah terverifikasi sehingga MLS1 dapat meneruskan traffic antar VLAN ketika packet dikirimkan antar local network.

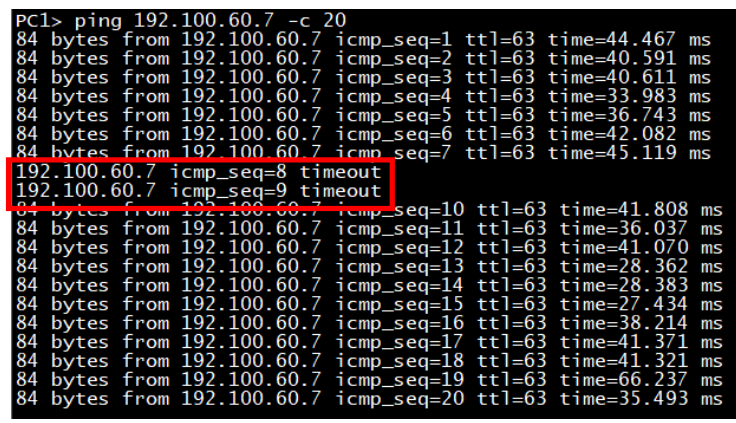

Gambar 12. Pengujian Koneksi Local Network

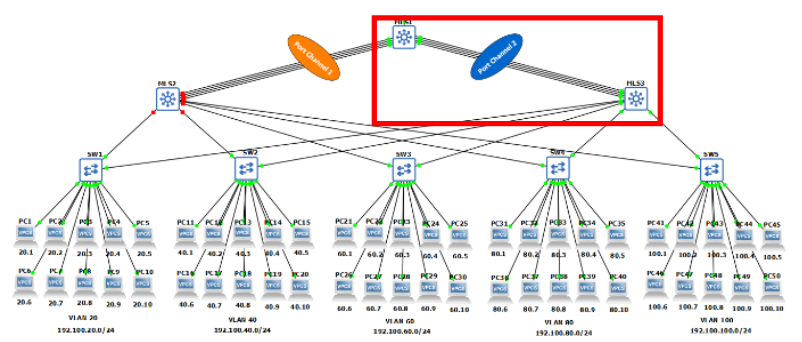

Gambar 13. Penonaktifan MLS2

Pada gambar 12 dan 13 dapat dilihat bahwa penonaktifan pada MLS2 ketika PC1 mengirim packet ke PC27 mengakibatkan proses pengiriman sempat terhenti namun dapat kembali terkirim, karena MLS3 dan port channel 2 tersedia untuk meneruskan pengiriman packet tersebut. Dengan penggunaan virtual interface pada interVLAN routing tipe SVI, traffic antar local network tetap terjaga ketersediaannya selama masih ada link lain yang dapat menggantikan link yang mengalami down. 


\section{Analisa QoS}

Untuk mengetahui performansi dari perancangan jaringan yang dibuat dilakukan analisa QoS (Quality of Service) menggunakan software Wireshark, dengan 2 parameter yang digunakan untuk pengujian yaitu packet loss dan delay. Pengujian dilakukan sebanyak 30 kali dengan melakukan ping ke provider. Kriteria penilaian dianalisa berdasarkan standarisasi ITU-T dengan kriteria packet loss dan delay seperti tabel berikut.

Tabel 3. Standarisasi ITU-T Packet Loss

\begin{tabular}{cc}
\hline Category & Packet Loss \\
\hline Good & $0-1 \%$ \\
Acceptable & $1-5 \%$ \\
Poor & $5-10 \%$ \\
\hline
\end{tabular}

Tabel 4. Standarisasi ITU-T Delay

\begin{tabular}{cc}
\hline Category & Delay \\
\hline Excellent & $<150 \mathrm{~ms}$ \\
Good & $150-300 \mathrm{~ms}$ \\
Poor & $300-450 \mathrm{~ms}$ \\
Unacceptable & $>450 \mathrm{~ms}$ \\
\hline
\end{tabular}

\section{Packet Loss}

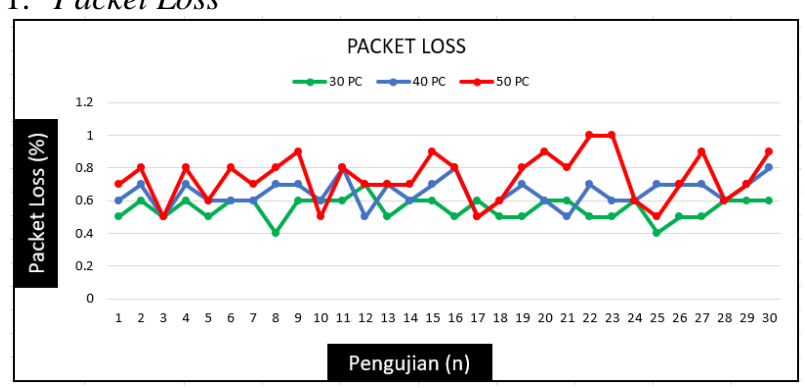

Gambar 14. Grafik Hasil Pengujian Packet Loss

Ketika pengujian berlangsung dilakukan pemutusan 4 link EtherChannel untuk mengetahui nilai packet loss yang dihasilkan dari proses konvergensi jaringan. Dari grafik gambar 14 dapat dianalisa pada 30 PC nilai minimum packet loss sebesar $0.4 \%$, maksimum sebesar $0.7 \%$ dan rata-rata dari total packet loss yang dihasilkan sebesar $0.55 \%$. Pada 40 PC nilai minimum packet loss sebesar $0.5 \%$, maksimum sebesar $0.8 \%$ dan rata-rata dari total packet loss yang dihasilkan sebesar $0.65 \%$. Pada 50 PC nilai minimum packet loss sebesar $0.5 \%$, maksimum sebesar $1 \%$ dan rata-rata dari total packet loss yang dihasilkan sebesar $0.74 \%$.

\section{Delay}

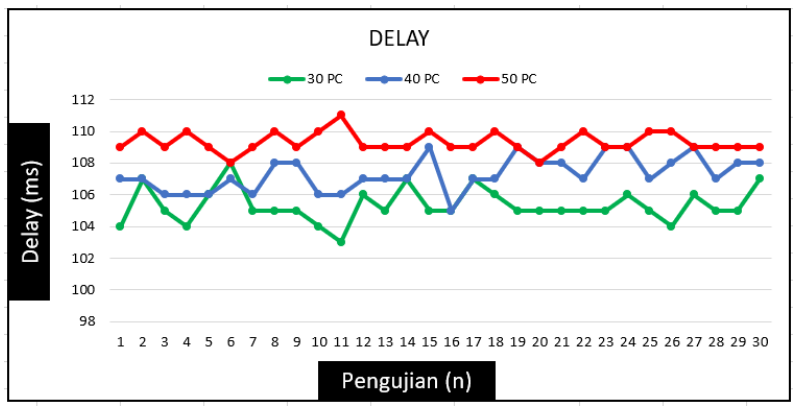

Gambar 15. Grafik Hasil Pengujian Delay

Pada parameter delay juga menggunakan skenario yang sama untuk mengetahui delay yang dihasilkan dari proses konvergensi jaringan. Dari grafik gambar 15 dapat diketahui pada 30 PC nilai minimum delay sebesar 103 $\mathrm{ms}$, maksimum sebesar $108 \mathrm{~ms}$ dan rata-rata dari total delay ialah $105.33 \mathrm{~ms}$. Pada 40 PC nilai minimum delay sebesar $105 \mathrm{~ms}$, maksimum sebesar $109 \mathrm{~ms}$ dan rata-rata dari total delay ialah $107.30 \mathrm{~ms}$. Pada 50 PC nilai minimum delay sebesar $108 \mathrm{~ms}$, maksimum sebesar 111 $\mathrm{ms}$ dan rata-rata dari total delay ialah $109.30 \mathrm{~ms}$.

\section{Kesimpulan}

\section{Kesimpulan}

Hasil dari penggunaan teknologi EtherChannel LACP dapat meningkatkan ketersediaan jaringan dan mengatasi permasalahan konektivitas jaringan LAN. Terlihat ketika pengujian pemutusan link dilakukan, packet tetap dapat terkirim dengan cepat dan tanpa perlu penanganan secara manual. Saat proses flooding juga didapatkan kinerja penyeimbang beban kerja jaringan yang membuat pengiriman packet dari setiap client yang berbeda menggunakan semua link EtherChannel yang tersedia, sehingga meminimalisir terjadinya penumpukan traffic pada 1 jalur atau terjadinya overload. Penggunaan interVLAN routing tipe SVI juga memudahkan antar VLAN atau network yang berbeda dapat saling terhubung melalui default gateway pada virtual interface.

Dari analisa QoS dapat disimpulkan bahwa perancangan jaringan yang dibuat memiliki performansi yang baik di mana setiap nilai rata-rata packet loss kurang dari $1 \%$ dan nilai delay kurang dari $150 \mathrm{~ms}$ pada kondisi 30 PC, 40 PC dan 50 PC. Hal tersebut merujuk pada standarisasi ITU-T bahwa delay $<150 \mathrm{~ms}$ adalah bagus begitu juga pada packet loss $0-1 \%$. Semakin banyak jumlah PC yang digunakan maka semakin tinggi juga nilai packet loss dan delay, sebab traffic semakin padat.

\section{Saran}

Perancangan redundancy link dan load balancing dapat dikembangkan dengan skema jaringan yang lebih kompleks dengan dikombinasikan metode lain seperti GLBP (Gateway Load Balancing Protocol), serta melakukan penambahan dari segi keamanan seperti menggunakan port security dan ACL (Access Control 
List) untuk membuat pembatasan hak akses dan sistem filtering pada jaringan yang digunakan.

\section{Daftar Pustaka}

[1] Khaing Khaing Wai, "Network Level Redundancy for Campus LAN," Int. J. Trend Sci. Res. Dev. Int. J. Trend Sci. Res. Dev., vol. 3, no. 5, pp. 1738-1743, 2019.

[2] I. A. Alimi, "Bandwidth Management and Loop Prevention in Redundant Networks," Am. J. Mob. Syst. Appl. Serv., vol. 2, no. 1, pp. 1-12, 2016.

[3] W. H. Pamungkas and E. Prayitno, "Perancangan Jaringan Redundancy Link Menggunakan Konsep HSRP dan Etherchannel," METIK J., vol. 2, no. 1, pp. 75-82, 2018.

[4] K. NUGROHO and M. S. FALLAH, "Implementasi Load Balancing menggunakan Teknologi
EtherChannel pada Jaringan LAN," ELKOMIKA J. Tek. Energi Elektr. Tek. Telekomun. Tek. Elektron., vol. 6, no. 3, pp. 420-435, 2018.

[5] I. Journal and D. In, "Design and Implementation of LACP Protocol in L3 ( Layer3 ) Switch," vol. 5, no. 5, pp. 253-257.

[6] Z. Amin, "Simulasi Dan Perancangan Keamanan Autentikasi Jaringan Hirarki Link Aggregation Control Protocol (LACP) Berbasis Router Cisco (Studi," vol. 3, no. September, pp. 138-144, 2014.

[7] P. H. Sutanto, "Perancangan Virtual Local Area Network Berbasis VTP Dan Inter-Vlan Routing," J. Tek. Komput., vol. IV, no. 2, pp. 125-134, 2018.

[8] N. H. Prasad, B. Amarnath, B. K. Reddy, and M. Puthanial, "Intervlan Routing and Various Configurations on Vlan in a Network using Cisco Packet Tracer," vol. 2, no. 11, pp. 749-758, 2016. 